\title{
Dossier Juventudes y Política. Una Introducción
}

\author{
Mercedes Oraisón* \\ María Cristina Sánchez León** \\ Bruno Bivort $^{* * *}$
}

En los últimos tiempos se registra un auge de los estudios sobre jóvenes y su relación con la política que da cuenta de su revalorización como actores claves en los procesos sociales de transformación, y en los impulsos democratizadores de las instituciones, de lo que algunos de los acontecimientos del mundo y la región de este último tiempo son evidencia.

Apartados de las formas tradicionales de participación política y de los mecanismos formales para el ejercicio de la ciudadanía, los jóvenes han participado activamente y han liderado las protestas en las calles Brasil, Egipto, Grecia, Islandia, Rusia, España, Túnez, Ucrania, Estados Unidos, México, Colombia y Chile. Han alzado la voz contra los problemas ambientales, la corrupción político-empresarial, la falta de democracia y justicia social. En los últimos cinco años han logrado el reconocimiento social y la visibilización de las desigualdades y de la falta de oportunidades y posibilidades para una vida digna donde prevalezca el respeto a los derechos humanos.

Pero las construcciones sobre la condición de juventud son contingentes, el "ser joven" se configura en referencia a un contexto histórico, social, cultural y, particularmente, político. Los jóvenes aparecen en escena o son invisibilizados según el momento y el contexto en el que se los piensa e interpela. La literatura sobre esta cuestión es profusa y revela diferentes posicionamientos de la sociedad, las políticas públicas y las instituciones que los asisten y demarcan.

En la última década han empezado a emerger trabajos sobre la juventud que la insertan con espacios, prácticas, organizaciones y acciones no tradicionales. Los diferentes estudios sobre los jóvenes y su vinculación con la política en América Latina revelan sus diversas dinámicas de interacción y expresión cultural, sus distintas luchas y demandas, sus formas de participación, de representación y de resistencia.

\footnotetext{
* CES - UNNE - Argentina.

** Universidad de Manizales - Colombia.

*** Universidad del Bio Bio - Chile.
} 
La sección monográfica del cuarto número de De prácticas y discursos. Cuadernos en ciencias sociales está dedicada a visualizar e indagar en las múltiples y complejas vinculaciones entre las juventudes, la condición juvenil y la política: los procesos de socialización y subjetivación de los jóvenes, sus construcciones discursivas de la política, lo político, la democracia y la ciudadanía y sus prácticas y repertorios de acción y posicionamiento en el espacio público-político. Esta entrega reúne un escrito de Miriam Kriger, quien por sus antecedentes es considerada una referente clave en el tema en cuestión, un conjunto de artículos de autores provenientes de distintos países de Latinoamérica y tres reseñas de libros recientemente publicados dedicados a esta temática.

El artículo de Kriger ofrece un interesante análisis de las representaciones juveniles sobre lo político y la política a partir de un estudio realizado con estudiantes secundarios. El propósito de este se centró en examinar cómo se relacionan ambos aspectos luego de que indagaciones previas, en el contexto posterior a la crisis del 2001, dieran cuenta de un antagonismo entre la clase política y la ciudadanía. Los resultados obtenidos en el presente estudio, sin embargo, le permiten sostener a la autora que los jóvenes estudiados están involucrados en un proceso de repolitización en el que las nociones de lo político y la política han sido resignificadas y se ha producido una especie de rearticulación o acercamiento.

La tensión entre lo político y la política aparece como una de las tangentes entre los artículos que componen el dossier. Otros ejes en torno a los cuales giran los artículos presentados en el dossier son la vinculación de los jóvenes y la ciudadanía, las representaciones y estigmatizaciones de la juventud, las significaciones de los jóvenes sobre sus prácticas sociales y políticas y las interpelaciones de las instituciones en cuyo marco se configura el ser joven y la condición juvenil.

En el artículo Espacios alternativos de formación en la construcción de culturas políticas: una propuesta para su análisis, Amelia Molina García presenta algunas reflexiones sobre los conceptos que se han generado a partir del estudio de la juventud y la acción política, en el marco de una investigación sobre cultura política juvenil. En este texto analiza los procesos de conformación de identidades y cultura política de jóvenes que participan de una experiencia del Consejo Nacional de Fomento Educativo (CONAFE), considerándola como un espacio de formación y ejercicio de ciudadanía.

En este artículo, se revisan los tipos de identidades que los jóvenes logran construir siguiendo el esquema propuesto por Castells. La experiencia de Integradores Comunitarios ha favorecido la participación activa de los jóvenes, quienes al redefinir su posición social se han constituido en actores que se subjetivan por lo que hacen, por lo que valoran y por las relaciones en que se encuentran comprometidos. 
La incidencia de los espacios y experiencias juveniles en la construcción de ciudadanía está igualmente presente en el artículo de Jorge Saraví Práctica del skate, ciudadanía y participación política en jóvenes platenses. Para Saraví las luchas de los jóvenes skater para la construcción de un skatepark se constituyen en auténticas experiencias de afirmación de la ciudadanía. En este marco ellos buscan un lugar en la sociedad y en la ciudad, "a través de su visibilización como estrategia política, intentan hacer que sus prácticas sean aceptadas y valoradas", construyen un conjunto de discursos que se apropian de temas centrales para la ciudadanía, como los derechos de los ciudadanos, el uso de los espacios públicos y el cuidado del patrimonio urbano, entre otras cuestiones de interés. "Toda la disputa y el proceso por lograr la construcción de un skatepark encierra una necesaria definición de qué es lo legitimo en la ciudad y de quién puede definir y cómo esa legitimidad".

Tensiones y paradojas en la configuración de la identidad ciudadana en la escuela secundaria es un tercer artículo que también explora la constitución de la subjetividad política y ciudadana en los jóvenes pero desde los modelos de identificación que la escuela propicia. En este texto Rodríguez Mc Keon examina "algunos de los significados que producen, circulan y dan sentido a la arquitectura del dispositivo escolar, en el entendido de que allí se condensan maneras específicas de dinamizar la construcción del nosotros, de procesar la diferencia y de delimitar el margen de intervención de los sujetos en la producción y modificación del orden social lo que da como resultado la configuración de determinados modos de reconocerse como ciudadanos". Los resultados de este estudio dan cuenta de que en la escuela actual aún existen distintos mecanismos y estrategias que organizan las relaciones de saber-poder para favorecer que los jóvenes se asuman como ciudadanos delimitando márgenes de acción determinados sobre sí mismos, con los otros y el mundo, conformando procesos de identificación ciudadana que se estructuran a través del principio de lo "absolutamente escolar". Para la autora la "finalidad de dicho principio es obturar la manifestación de cualquier diferencia, debido a que ello supondría legitimar el derecho a decidir de los jóvenes en tanto 'sujetos de derecho'".

El artículo de Luis Gerardo Gabaldón Empoderamiento juvenil y control policial informal, propone otra discusión en torno a modos en que la población juvenil es regulada socialmente. Este autor pone en cuestión la aplicación de mecanismos altamente coactivos de control social informal de la juventud percibida como desviada o incluso rebelde utilizando como marco referencial la noción de vulnerabilidad vinculada a carencias asociadas a la indefinición de identidades, la atenuación de controles informales benignos, la insuficiencia o ineficacia del control social formal, las debilidades socioeconómicas y la exclusión social. En contraposición, se plantea la idea del empoderamiento juvenil; concepto que "pasa por la atribución y el reconocimiento 
de identidades legítimas y toleradas a los jóvenes, sin esperar alcanzar la recuperación del control familiar y comunal o la ocupación efectiva del espacio del control social formal garantista por el otro, aspectos que resultan problemáticos a corto plazo". De lo que se trata es de promover el reconocimiento de los jóvenes como sujetos morales, con capacidad de asumir responsabilidades y acumular respetabilidad. El autor advierte que la construcción de identidades legítimas está asociada a factores como el empleo y los ingresos lícitos, la responsabilidad frente a los miembros de la comunidad, la energía creadora y la manifestación de conductas altruistas.

Con muchos puntos de contacto con el artículo anterior, en Lo político y las políticas de la delincuencia juvenil. Una reflexión del caso de jóvenes vinculados al Sistema de Responsabilidad Penal Adolescente. Bogotá-Colombia Ana Cienfuegos reflexiona sobre las políticas para la prevención de la delincuencia juvenil. Estas consideraciones se enmarcan en un estudio realizado por la autora en torno a los sentidos y significados del delito en jóvenes vinculados al Sistema de Responsabilidad Penal Adolescente (SRPA) en Bogotá, Colombia. Los resultados rescatan los sentidos y significados que los jóvenes otorgan a dimensiones y escenarios de su vida asociados con lo político y recomendaciones frente a las políticas de prevención y atención de la delincuencia juvenil.

Dice Cienfuegos que los "relatos juveniles analizados en este artículo dejan ver que la problemática de la delincuencia juvenil no es solo un asunto técnico que debe resolverse desde la intervención punitiva y/o asistencial, es al parecer también un asunto político que implica la comprensión de la naturaleza de identidades colectivas en contextos de exclusión social y el reconocimiento de los jóvenes vinculados al delito como actores con necesidades socio-políticas desatendidas".

Un último artículo que forma parte del dossier, Representaciones en la prensa norpatagónica de las juventudes militantes (2001-2007) de Emilse Malke Kejner analiza el discurso del diario Río Negro $(R N)$ sobre las juventudes militantes de principios del siglo XXI en la Patagonia norte. Este trabajo se propone estudiar las juventudes organizadas urbanas más allá del conurbano bonaerense, visibilizar la intervención de estos sujetos en la política en los últimos años y revistar la forma en que fueron representados.

Para esta autora comprender cómo se resignifican esas representaciones permite desmontar los sentidos del término "juventud" de acuerdo a su funcionamiento discursivo. Entre los resultados encontrados se destaca que para las juventudes, el diario $R N$ privilegia las funcionalizaciones por sobre las identificaciones, que son aquellas formas en que los actores sociales son definidos no por lo que hacen, como en el primer caso, sino por lo que, más o menos permanente e inevitablemente, son; por ejemplo, jóvenes. "La identificación de los actores como 'jóvenes' es reemplazada en el 
diario por algunas funcionalizaciones que actúan como identidades, como la de 'ceramistas', o generan colectivos de identificación, como 'desocupados'".

Los distintos artículos aquí reunidos permiten advertir distintos procesos sociales y políticos en los que los jóvenes participan y en cuyo marco se subjetivan. De este modo, se pone en evidencia que la juventud se constituye en múltiples adscripciones y articulaciones que configuran diversos posicionamientos, identidades y subjetividades juveniles y sobre algunos de los principales desafíos que los gobiernos, instituciones y organizaciones que trabajan con los jóvenes tendrán que asumir en forma reflexiva, crítica y proactiva.

Los jóvenes seguirán participando de diversas y nuevas formas en aquellos procesos que afecten sus vidas, las preguntas que surgen son ¿cómo harán esto?, ¿lo harán desde los espacios que la sociedad defina para su inclusión?, ¿qué propósitos los mueven? y ¿de qué forma ejercerán sus acciones?, esperamos que este número bibliográfico sea una contribución para ir despejando estas incógnitas y dinamizar el debate en torno a las múltiples y complejas vinculaciones entre las juventudes, la condición juvenil y la política. 